\title{
Comunicação
}

[Communication]

\section{Perfil fenotípico de linfócitos periféricos de bovinos de raças européias}

[Phenotypic profile of peripheral blood lymphocytes from European bovines]

\author{
J.F.F. Bittar ${ }^{1}$, M.F.B. Ribeiro ${ }^{2}$, A.P.V. Marciano ${ }^{3}$, J.H.P. Salcedo ${ }^{4}$, O.A. Martins-Filho ${ }^{5}$ \\ ${ }^{1}$ Instituto de Estudos Avançados em Veterinária da Universidade de Uberaba \\ Avenida Nenê Sabino, 1801 \\ 38050-501 - Uberaba, MG \\ ${ }^{2}$ Departamento de Parasitologia do Instituto de Ciências Biológicas - UFMG, Belo Horizonte \\ ${ }^{3}$ Bolsista de iniciação científica - CNPq - Centro de Pesquisa René Rachou \\ ${ }^{4}$ Departamento de Biotecnologia Aplicado à Agropecuária - UFV, Viçosa \\ ${ }^{5}$ Laboratório de Doenças de Chagas - Centro de Pesquisa René Rachou - Fundação Oswaldo Cruz
}

A babesiose bovina constitui um dos principais problemas sanitários dos rebanhos bovinos de carne e leite dos países de clima tropical e subtropical. Trabalhos foram desenvolvidos visando controlar a enfermidade por meio de métodos mais eficazes como a vacinação com subunidades do hemoparasito, com parasitos atenuados, com proteínas recombinantes ou com peptídeos sintéticos (Timms, 1989; Callow, Mellors, 1966; Taylor 1989; Reduker et al., 1989; Dalrymple, 1993; Palmer, McElwain, 1995). Entretanto, a produção de vacina para a babesiose bovina, encontra entraves referentes às dificuldades de testá-la experimentalmente. As babesias são espécies específicas e não se multiplicam dentro de hemácias de outros animais como camundongos, ratos ou outros animais de laboratório. Essa dificuldade faz com que as pesquisas necessitem de bovinos livres de hemoparasitoses e áreas livres de carrapatos, uma vez que esse ectoparasito é o principal vetor da doença.

Outro empecilho para o desenvolvimento de vacinas refere-se aos exames realizados para avaliar o grau de proteção imunológica que normalmente considera a resposta imune humoral. Segundo Wright et al. (1983) e Goodger et al. (1986), a imunidade protetora não está diretamente relacionada aos níveis de anticorpos porque os anticorpos totais são produzidos contra antígenos do parasita e contra antígenos do hospedeiro como resultado de resposta inflamatória. Portanto, para a avaliação da eficácia da vacina para a babesiose deveriam ser utilizados testes para a análise das respostas humoral e celular.

Outra dificuldade refere-se à origem dos bovinos. Os de origem européia (Bos taurus) são geneticamente mais susceptíveis à babesiose quando comparados aos de origem indiana (Bos indicus) (Francis, Little, 1964; Francis, 1996; Johnston et al., 1978; Bock et al., 1999), porém, em relação ao Bos taurus não há citações de qual raça seria mais susceptível.

Apesar de os testes vacinais serem feitos com bovinos puros e de uma mesma raça, os animais não são isogênicos e com isso as respostas não são uniformes. Provavelmente isso se deve à característica polimórfica dos genes que codificam as moléculas do major histocompatibility complex (MHC), os quais são de fundamental importância na apresentação de antígenos, na comunicação bioquímica entre as células do sistema imune e no reconhecimento de antígenos próprios e não próprios (Klein et al., 1993; Hughes, Yager, 1998; Freitas, 2001).

Recebido para publicação em 12 de novembro de 2002

Recebido para publicação, após modificações, em 3 de setembro de 2003

E-mail: joelyff@hotmail.com 
O presente trabalho objetivou avaliar o perfil fenotípico de linfócitos de bovinos de origem européia (Bos taurus) das raças Holandesa, Hereford e Pardo-Suíça, com o intuito de avaliar a existência de variações de CD4, CD8 e CD21.

Foram utilizados 18 animais, Bos taurus, com idades acima de cinco meses, livres de carrapatos e hemoparasitoses, sendo nove da raça Holandesa, seis da Hereford e três da PardoSuíça. Os animais recém-nascidos, após a ingestão do colostro, foram mantidos em isolamento. Amostras de sangue em EDTA foram colhidas por punção da veia jugular e mantidas à temperatura ambiente (TA) até a realização da imunofenotipagem. Os ensaios de citometria de fluxo para a imunofenotipagem dos linfócitos periféricos foram realizados conforme o protocolo desenvolvido especificamente para este estudo: em tubos de $5 \mathrm{ml}$ contendo $15 \mu \mathrm{l}$ de anticorpos monoclonais anti-CD4, anti-CD8 bovino marcados com isotiocianato de fluoresceína (FITC) e anticorpo anti-CD21 bovino purificado foram adicionados $30 \mu \mathrm{l}$ de sangue colhido em EDTA. Após incubação por 20 minutos à temperatura ambiente,

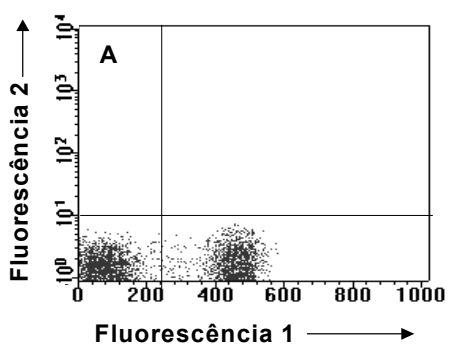

acrescentaram-se $50 \mu \mathrm{l}$ do anticorpo secundário marcado com FITC ao tubo contendo anti-CD21 purificado. Após incubação, todas as preparações celulares foram submetidas à lise de eritrócitos, acrescentando-se $2 \mathrm{ml}$ de solução de lise ${ }^{1}$. Os leucócitos totais foram lavados em PBS, fixados com $200 \mu 1$ de solução fixadora (paraformaldeído $1 \%$ em tampão cacodilato de sódio $10 \mathrm{~g} / 1, \mathrm{pH} 7,2$ ) e analisados no citômetro de fluxo $^{2}$ (Fig 1). Foram feitas análise de variância e comparação de médias pelo teste t de Student.

Os animais apresentaram diferentes perfis fenotípicos de linfócitos circulantes, de acordo com a raça (Tab.1) a qual pertenciam. Observouse diferença entre as raças Holandesa e Hereford quanto à porcentagem de linfócitos $\mathrm{T} \mathrm{CD}^{+} \mathrm{e}$ $\mathrm{CD}^{+}$, entretanto, o mesmo não ocorreu quanto à porcentagem de linfócitos $\mathrm{B} \mathrm{CD} 21^{+}$. Os da raça Holandesa apresentaram menor porcentagem de linfócitos $\mathrm{T}$ totais $\left(\mathrm{CD}^{+}\right.$e $\left.\mathrm{CD}^{+}\right)$e maior porcentagem de linfócitos $\mathrm{B}\left(\mathrm{CD} 21^{+}\right)$em relação aos da raça Hereford, bem como menor razão T/B (Fig. 2). Não foi observada diferença entre as raças quanto à razão $\mathrm{TCD}^{+} \mathrm{e} \mathrm{TCD}^{+}$(Fig. 2).

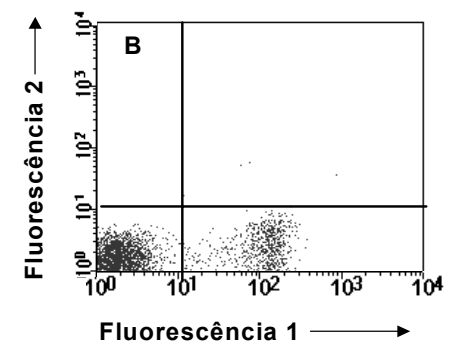

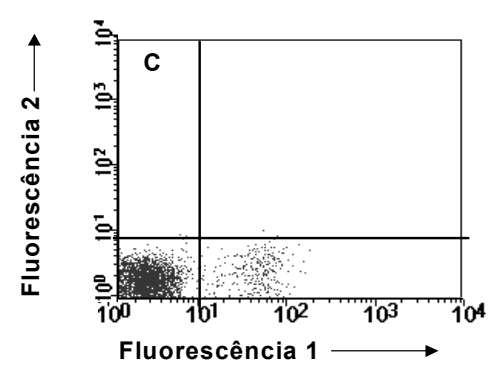

Figura 1. Representação gráfica da população de linfócitos bovinos marcada com o anticorpo monoclonal anti CD4 (A), CD8 (B) e CD21 (C).

\footnotetext{
${ }^{1}$ FACS $^{\mathrm{TM}}$ Lysing Solution

${ }^{2}$ FACScalibur - BECTON DICKINSON
} 
Tabela 1. Porcentagem de linfócitos $\mathrm{T}\left(\mathrm{CD}^{+}{ }^{+}\right.$e $\left.\mathrm{CD} 8^{+}\right)$e $\mathrm{B}\left(\mathrm{CD} 21^{+}\right)$do sangue periférico de bovinos das raças Holandesa, Pardo-Suíça e Hereford

\begin{tabular}{lccc}
\hline Raça & Linfócitos T CD4 $^{+}$ & Linfócitos T CD $^{+}$ & Linfócitos B CD21 $^{+}$ \\
\hline Holandesa & $25,32 \pm 6,4 \mathrm{a}$ & $17,82 \pm 5,09 \mathrm{a}$ & $18,58 \pm 9,32 \mathrm{a}$ \\
Suíça & $32,39 \pm 0,93 \mathrm{ab}$ & $24,56 \pm 7,94 \mathrm{ab}$ & $14,92 \pm 5,56 \mathrm{a}$ \\
Hereford & $37,69 \pm 9,69 \mathrm{~b}$ & $28,15 \pm 7,65 \mathrm{~b}$ & $12,25 \pm 3,36 \mathrm{a}$ \\
\hline
\end{tabular}

Valores seguidos de letras iguais na coluna não diferiram entre si $(\mathrm{P} \leq 0,05)$ pelo teste $\mathrm{t}$.
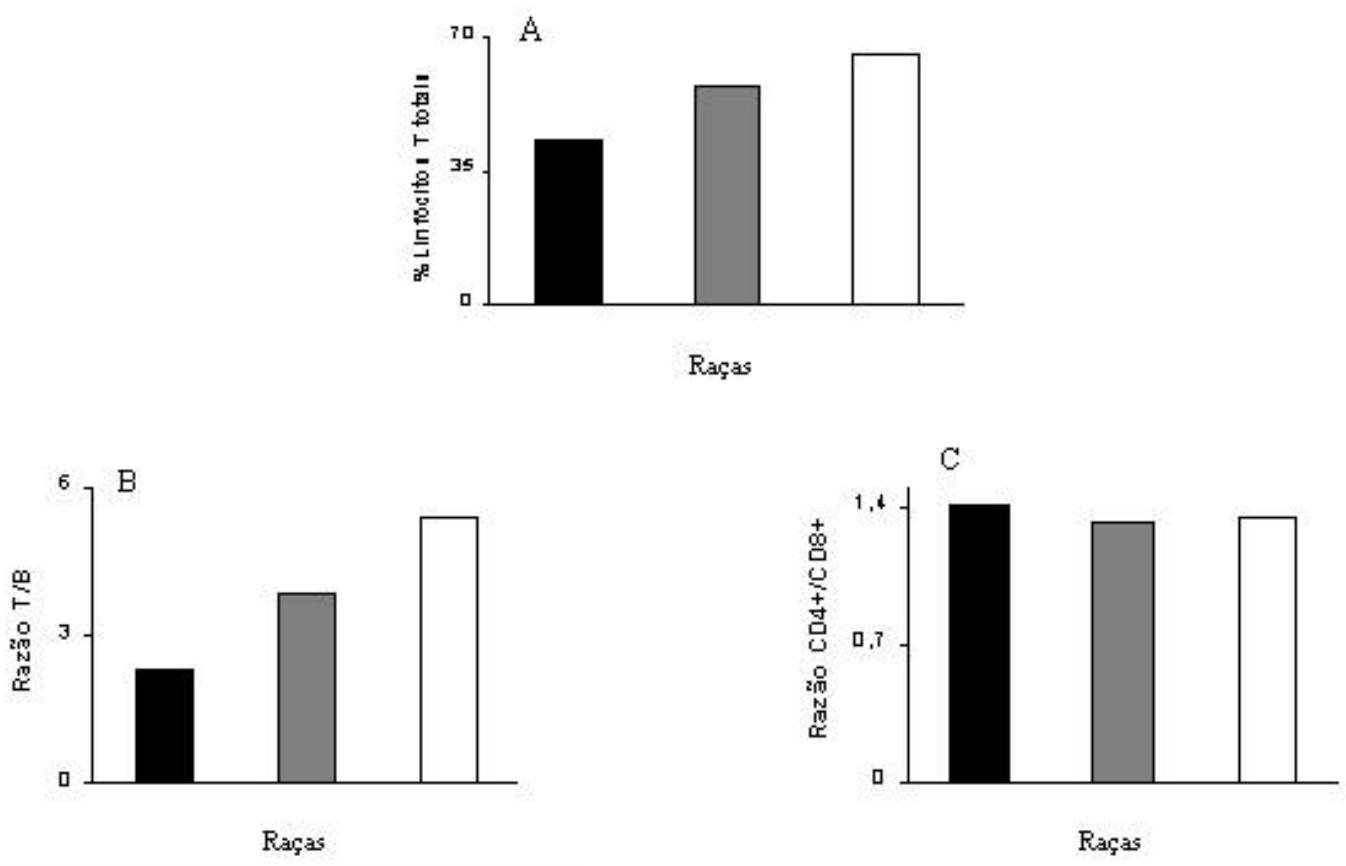

Figura 2. Porcentagem de linfócitos $\mathrm{T}$ totais (A) e razão entre linfócitos T/B (B) e T CD4 $4^{+} / \mathrm{CD}^{+}$(C) no sangue periférico de bovinos das raças Holandesa (preto), Pardo-Suíça (cinza) e Hereford (branco).

Estes dados sugerem que o perfil fenotípico do sangue periférico dos bovinos europeus pode influenciar o padrão de imunidade clínica apresentado por eles. Assim, baixos níveis de linfócitos T (CD4 e CD8) e elevados níveis de linfócitos $\mathrm{B}$ em animais da raça Holandesa podem estar associados à sua susceptibilidade para infecções por Babesia, enquanto que elevados níveis de linfócitos $\mathrm{T}$ e baixos níveis de linfócitos $\mathrm{B}$ podem estar associados à maior resistência para infecções parasitárias. A elevada razão $\mathrm{T} / \mathrm{B}$ pode estar associada à resistência dos animais Hereford à infecções por Babesia.
Portanto, a existência de um perfil fenotípico diferencial de linfócitos circulantes em animais das raças Holandesa, Pardo-Suíça e Hereford deve ser considerada nos estudos da imunidade celular desencadeada por doenças infectoparasitárias em bovinos, uma vez que essas diferenças podem ser relevantes para o padrão de resposta imune apresentado por esses animais.

Palavras - chave: imunofenotipagem, citometria de fluxo, vacina, babesiose bovina 


\begin{abstract}
The phenotypic profile of bovine lymphocytes was evaluated in 18 bovines (Bos taurus) from three different breeds, being nine Holstein, six Hereford, and three Brown Swiss. All animals were free from ticks and hemoparasites, as determined after jugular vein blood sampling. The immunophenotypes of peripheral lymphocytes were evaluated by flow cytometry. Peripheral lymphocytes were exposed to bovine fluorescein-labeled monoclonal antibodies including anti-CD4, anti-CD8, and anti-purified bovine CD21 specificities. After lysing the erythrocytes with a commercial lysing solution (FACS TM), the lymphocytes were washed, fixed, and evaluated by flow cytometry. Significant differences in the phenotypic profiles of peripheral lymphocytes among all breeds were found. Holstein animals showed a lower percentage of total $T$ lymphocytes (CD4 and CD8) and higher percentage of B lymphocytes (CD21). In addition, the lymphocytes from Holstein animals showed a lower T/B ratio than the lymphocytes from Hereford animals. These results suggest the existence of different phenotypic profiles of peripheral lymphocytes from European breeds of cattle. Such differences may be related to the different pattern of immune response described for these breeds in the literature and may account to varying disease resistance among breeds.
\end{abstract}

Keywords: immunophenotyping, flow cytometry, vaccine, bovine babesiosis

\section{REFERÊNCIAS BIBLIOGRÁFICAS}

BOCK, R.E.; KINGSTON, T.G.; STANDFAST, N.F. et al. Effect of cattle breed on innate resistance to inoculations of Babesia bigemina. Aust. Vet. J., v.77, p.465-466, 1999.

CALLOW, L.L.; MELLORS, L.J. A new vaccine for Babesia argentina infection prepared in splenectomized calves. Aust. Vet. J., v.42, p.464-465, 1966.

DALRYMPLE, B.P. Molecular variation and diversity in candidate vaccine antigens from Babesia. Acta Trop., v.53, p.227-238, 1993.

FRANCIS, J. Resistance of zebu and other cattle to tick infestation and babesiosis with special reference to Australia: an historical review. Brit. Vet. J., v.122, p.301-307, 1966.

FRANCIS, J.; LITTLE, D.A. Resistance of drought master cattle to tick infestation and babesiosis. Aust. Vet. J., v.40, p.247-253, 1964.

FREITAS, C.M.B. Resposta imune induzida por Babesia bovis (Starcovicci, 1983): reconhecimento e ativação ex vivo de peptídeos sintéticos e eventos celulares em linfonodos de bovinos. 2001. 91f. Dissertação (Mestrado). Universidade Federal de Viçosa, Viçosa, MG.

GOODGER, B.V.; COMMINS, M.A.; WRIGHT, I.G. et al. Babesia bovis: vaccination trial with a dominant immunodiffusion antigen in splenectomized calves. $Z$. Parasitenk., v.72, p.715-722, 1986.
HUGHES, A.L.; YEAGER, M. Natural selection at major histocompatibility complex loci of vertebrates. Annu. Rev. Genet., v.32, p.415-435, 1998.

JOHNSTON, L.A.Y.; LEATCH, G.; JONES, P.N. The duration of latent infection and functional immunity in drought master and Hereford cattle following natural infection with Babesia argentina and Babesia bigemina. Aust. Vet. J., v.54, p.14-18, 1978.

KELLEY, R.B. Zebu-cross cattle in Northern Australia: an ecological experiment. Melbourne: Council Science Industr. Research, 1943. 96p. (Bulletin n. 172).

KLEIN, J.; TAKAHATA, N.; AYALA, F.J. MHC polymorphism and human origins. Sci. Am., v.269, p.78-83, 1993.

PALMER, G.H.; MCELWAIN, T.F. Molecular basis for vaccine development against anaplasmosis and babesiosis. Vet. Parasitol., v.57, p.233-253, 1995.

REDUKER, D.W.; JASMER, D.P.; GOFF, W.L.; et al. A recombinant surface protein of Babesia bovis elicits antibodies that react with live merozoites. Mol. Biochem. Parasitol., v.35, p.239-248, 1989.

TAYLOR, S.M. Babesia vaccines attenuated by blood passage and irradiation. In: WRIGHT, I.G. Veterinary protozoan and hemoparasite vaccines. Boca Raton: CRC, 1989. p.43-59.

TIMMS, P. Development of babesial vaccines. Transc. R. Soc. Trop. Med. Hyg., v.83, p.73-79, 1989.

WRIGHT, I. G.; WHITE, M.; TRACEY-PATTE, P.D. et al. Babesia bovis: isolation of a protective antigen by using monoclonal antibodies. Infect. Immunol., v.41, p.244-250, 1983. 